\title{
Aortic regurgitation due to syphilis: unusual case
}

\author{
N O'FARRELL \\ From the Department of Genitourinary Medicine, King's College Hospital, London
}

SUMMARY A 28 year old man developed signs and symptoms of left ventricular failure and was found to have gross aortic regurgitation. He underwent an aortic valve replacement, and histology showed changes characteristic of syphilis. Both the age of this patient and the mode of presentation were atypical of cardiovascular syphilis.

\section{Case report}

A 28 year old heterosexual storekeeper of Portuguese Indian extraction presented with a two week history of cough and progressive shortness of breath, the onset of which coincided with a febrile illness. His appetite had decreased and he had lost over three kilograms in weight. His only ever sexual contacts had been with a prostitute in Goa two years previously and two prostitutes in Kenya 10 years previously. There had been no history of sexual abuse as a child, but 10 years previously he had been tattooed on his forearm.

Physical examination showed evidence of left ventricular failure, cardiomegaly, and the characteristic murmur of aortic regurgitation. Chest radiography, electrocardiography and echocardiography confirmed these findings. His blood pressure was $130 / 40 \mathrm{~mm} \mathrm{Hg}$.

The patient responded to conventional treatment for heart failure, and cardiac catheterisation showed severe aortic regurgitation. Serology showed positive results to the Treponema pallidum haemagglutination assay (TPHA) and the Venereal Disease Research Laboratory (VDRL) test at a titre of $1 / 256$, the erythrocyte sedimentation rate was $47 \mathrm{~mm}$ in the first hour, and the white cell count was $12.2 \times 10^{6} / 1$. Treatment was started with prednisolone for 48 hours followed by procaine penicillin $600 \mathrm{mg}$ and probenecid $500 \mathrm{mg}$ every six hours.

An aortic valve replacement was performed, and at operation there was pronounced mediastinal oedema and tense serous pericardial effusion. A size 25 Medtronic-Hall tilting disc prosthesis was inserted.

Address for reprints: Dr T McManus, Alexander Clinic, Department of Genitourinary Medicine, St Giles Hospital, St Giles' Road, London SE5 7RN

Accepted for publication 22 November 1986
Histology of the valve showed thickening of the intima with dense hyaline bands of collagen. The media and adventitia showed endarteritis and periarteritis of the vasa vasorum. Dense aggregates of

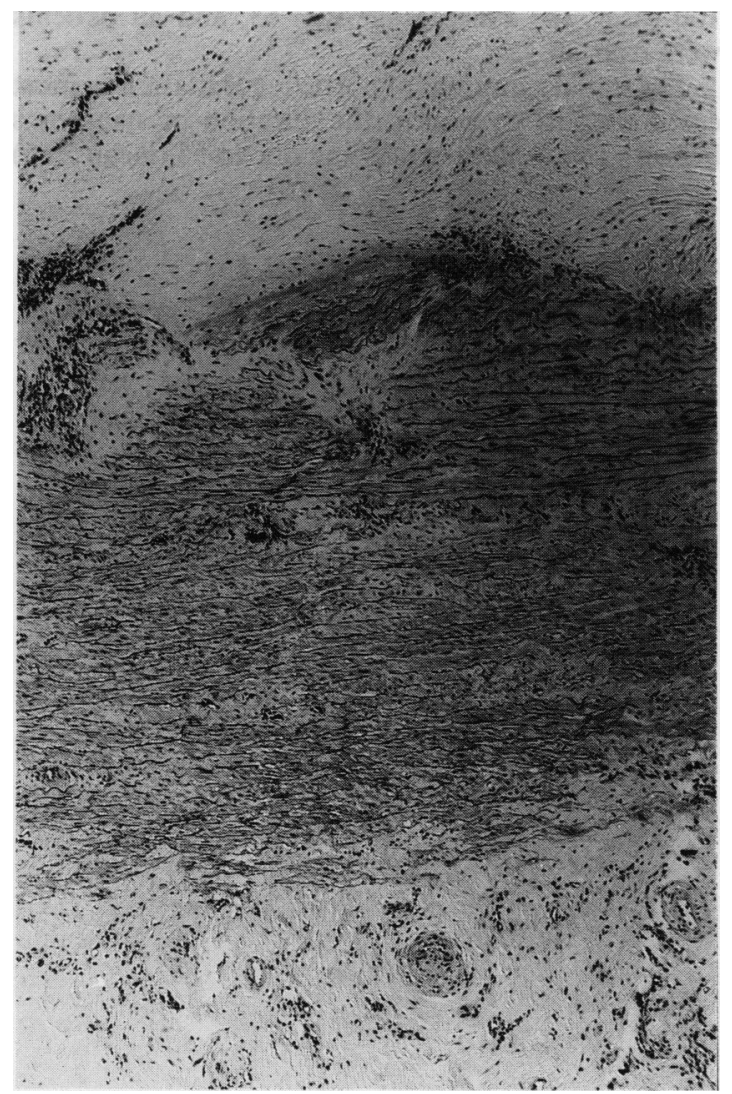

Figure Aortic valve histology showing intimal thickening and obliterative endarteritis of the vasa vasorum and periarteritis, mainly consisting of plasma cells with some lymphocytes (haematoxylin and eosin). 
lymphocytes and plasma cells were present, which caused disruption of the elastic fibre.

\section{Discussion}

Syphilis of the cardiovascular system is normally preceded by a latent period of 15 to 30 years, and most patients are aged 40 to 55 . The three main cardiac problems caused by syphilis are: thoracic aneurysm formation, aortic valve disease, or coronary ostial stenosis, whereas the myocardium is rarely affected directly. There is little evidence of any myocardial sequelae in surviving adolescents and adults with congenital syphilis, although $10 \%$ of infants dying of syphilis have myocarditis. ${ }^{1}$

Aortic regurgitation occurs in $30 \%$ of patients with tertiary syphilis, and in a series of 300 cases of aortic valve disease described by Campbell and Shackle, of which $25 \%$ were due to syphilis, nearly $80 \%$ were aged 40 to 60 , and none were younger than $30 .^{2}$ In Heggtveit's ${ }^{3}$ clinicopathological necropsy study of 100 cases, the average age was 63 , and all patients were over $30 .^{3}$

The initial symptom of aortic regurgitation in most cases is effort dyspnoea, the duration of symptoms before valve replacement being one to 55 (mean 25.5 ) months. ${ }^{4}$ Heart failure as a complication is said to be increasingly uncommon and to occur at a later stage of the disease. ${ }^{5}$

Valve surgery is not without risk, and one group had a mortality of $20 \%$ at operation and late mortality of $40 \%$ (unpublished observation) at a time when the mortality for aortic valve replacement in patients without syphilis at the National Heart Hospital was much lower.

The case described was most unusual both in the nature and presentation of symptoms and in the remarkably short latent period.

\section{References}

$1 \mathrm{McCulloch} \mathrm{H}$. Congenital syphilis as a cause of heart disease. Am Heart J 1930;6:136-41.

2 Campbell M, Shackle JW. A note on aortic valvular disease. $\mathrm{Br}$ Med J 1932;i:328-30.

3 Heggtveit HA. Syphylitic aortitis: a clinico-pathological study of 100 cases. Circulation 1964;29:346-55.

4 Grabau W, Emanuel R, Ross D, Parker J, Hegde M. Syphylitic aortic regurgitation: an appraisal of surgical treatment. British Journal of Venereal Diseases 1976;52:366-73.

5 Prewitt TA. Syphilitic aortic insufficiency. JAMA 1970;211:637-9. 